\title{
A INFORMAÇÃO E O CONHECIMENTO
}

Jacques Marcovitch

\begin{abstract}
Resumo: O texto analisa o impacto das novas tecnologias sobre o ensino e a pesquisa na área universitária. O cabedal de conhecimento acumulado pela universidade deve ser enriquecido pelas inovações tecnológicas e a USP vem realizando experiências neste sentido.

Palavras-chave: tecnologia; informação; universidade.

Abstract: This article analyzes the impact of new technologies on university teaching and research. The wealth of knowledge generated by universities should be enriched by technological innovation, and USP (University of São Paulo) is taking positive steps in this direction.

Key words: technology; information; university.
\end{abstract}

$\mathrm{A}$ tecnologia de informações é um instrumento essencial para o avanço e a difusão do conhecimento. No ano passado, em Washington, participando de um encontro promovido pela Associação das Universidades Americanas, tivemos oportunidade de testemunhar quanto esse processo mobiliza as atenções da academia moderna. Ali foram discutidas intensamente as possibilidades de avançar cada vez mais na digitalização dos acervos bibliográficos e teses, colocados à disposição dos interessados em conquistas do saber e programas de disciplinas.

Vivemos a iminência do surgimento de tecnologias cada vez mais sofisticadas na revolução digital, capazes de afetar profundamente a vida acadêmica. Há possibilidade real de que em 2020 surja um chip viabilizador de um trilhão de operações por segundo - o que corresponde a colocar em alguns milímetros cúbicos a capacidade de processamento do cérebro humano. Estamos diante de uma revolução irreversível, que John Brockman, idealizador do site Edge, chamou adequadamente de "terceira cultura", capaz de aproximar a elite científica de si mesma e do público, estimulando a troca intelectual.

Peter Drucker estava equivocado quando prognosticou, décadas atrás, o futuro das universidades. Foi um prog- nóstico superficial, prematuro e pessimista que felizmente não se realizou. Ao contrário do que ele previu, a tecnologia de informação não substituiu o convívio presencial na formação universitária. A pesquisa, a experimentação e a aprendizagem continuam dependendo bastante da freqüência presencial, e é bom que assim ocorra. A vivência no campus favorece a construção de relacionamentos, valores, afirmação de identidade, experiências culturais. Mas a informática, em todos os seus aspectos, é um instrumento complementar de grande valia. Com essa perspectiva, todas as grandes universidades do mundo estão concentrando os seus esforços na otimização dos serviços nessa área. O MIT está investindo 100 milhões de dólares para colocar os cursos de todos os seus professores em rede. $\mathrm{O}$ material disponibilizado inclui os programas, leituras, transparências e outros materiais didáticos. Isso aumenta o interesse de estudantes e outros docentes em conhecer pessoalmente os professores desses cursos, ampliando o universo dos que se beneficiam com os investimentos públicos.

Como Reitor da USP entre 1997 e 2001, orgulho-me de haver implementado uma Biblioteca Digital e espero das gestões futuras o esforço necessário para torná-la uma 
referência internacional de qualidade. Não nos falta para isso competência tecnológica e os recursos financeiros podem ser buscados externamente ou, como fizemos até agora, alocados em nosso orçamento. Contamos certamente com o apoio da comunidade interna, especialmente dos autores de teses, que são os elementos-chave do processo, uma vez que lhes cabe fazer a conversão do seu trabalho para o formato digital e submetê-lo ao sistema. Sendo esta ação voluntária, muito em breve poderemos saber o quanto os produtores de conhecimento estão interessados em partilhar o fruto do seu esforço intelectual.

A instalação na USP do projeto Cidade do Conhecimento foi outra prova do uso digital compartilhado. A comunicação em rede, nesse projeto, entre os universos do saber e do trabalho, é uma inovação que merece a atenção que a necessária interação da academia com a sociedade exige. Se foi bem-vinda a idéia de canalizar para a Biblioteca Digital da USP os conteúdos decorrentes desse diálogo, muito mais será o esforço de construir, a partir dessa conexão, um espaço para a negociação de políticas públicas e projetos de cidadania. As primeiras crianças a ingressar na Cidade do Conhecimento foram os ex-meninos de rua, integrantes do projeto Clicar, da Estação Ciência. A tecnologia da informação projetou, dessa forma, sua face mais humana e construtiva.

A entrada em nossa Biblioteca Digital dos conteúdos gerados nos debates promovidos pela Cidade do Conhecimento ampliará bastante as suas fronteiras, que são muito ambiciosas. A biblioteca encontra-se em fase de construção e muitas teses já foram incluídas. O seu objetivo de longo prazo é avançar na digitalização dos acervos bibliográficos da universidade e colocar à disposição dos interessados os programas de disciplinas e respectivos conteúdos.

É preciso usar a web como janela planetária para disponibilizar tais competências. Avançando nessa área a USP entrará em sintonia com as maiores universidades do mundo. O Instituto de Tecnologia de Massachusetts (MIT) anunciou recentemente que pretende colocar quase todos os seus 2 mil cursos na Internet, gratuitamente, até 2010. O caminho escolhido é o inverso do que vêm fazendo outros centros de ensino superior, que procuram criar novas fontes de renda, abrindo cursos pagos de ensino a distância. Para tornar o projeto viável, o MIT deverá criar sites de todos os cursos nos quais deverão constar anotações das aulas, lista de problemas, sumários, exames, simulações e vídeos - tudo a um custo de milhões de dólares. O presidente do Instituto, Charles M. Vest, não teme que os alunos deixem de pagar a anuidade para fazer o curso presencial quando poderão ter aulas e obter todo o material on-line, sem pagar. Disse o professor Charles que a disponibilização do ensino na web vai servir para atrair ainda mais estudantes para o MIT. Cito este fato para mostrar quanto é amplo o espaço que se abre para a tecnologia de informação no meio acadêmico. Estamos no limiar de uma era em que o ensino presencial e a difusão via Internet acabarão por se complementar. E essa complementação não se dará pelo sacrifício da educação como processo dialógico entre o professor e o aluno, entre a inteligência que ensina e a inteligência que aprende.

\section{SURPREENDENTE MUNDO NOVO}

A universidade, em face da revolução tecnológica, é igual a qualquer organização do nosso tempo. Não se pode ignorá-la e deixar de aproveitar todos os seus benefícios. Evidentemente, como centro crítico e questionador por natureza, jamais será uma usuária incondicional das oportunidades criadas pela tecnologia. Mas desconhecê-la ou deixar de aproveitá-la, quando necessário, é absolutamente imperdoável.

$\mathrm{O}$ crescimento do volume e dos meios de acesso às comunicações exige uma nova atitude mental das pessoas e das instituições. Há mudanças em marcha irreversível que não podem passar despercebidas. Tomemos alguns exemplos para dar ênfase a esta necessidade de observação.

Já existem protótipos de automóveis multienergéticos. Gasolina, gás natural e bateria elétrica são os três energéticos que alimentam o mesmo automóvel. Isso permite alguém vir do bairro de Santana, por exemplo, com gasolina, entrar na cidade com gás natural e, se tiver de passar em algum ponto mais poluído, ligar a bateria elétrica. Com isso o consumidor terá um automóvel com desempenho adequado para estrada e outras áreas de circulação, mantendo-se igualmente mais responsável, do ponto de vista ambiental.

$\mathrm{Na}$ área de saúde animal já estão sendo inseridos sensores em animais assim que nascem, para acompanhamento do seu metabolismo durante o ciclo de vida, podendo-se decidir qual a ração a ser consumida. Um laboratório já anunciou a modificação genética de uma vaca para que produza leite semelhante ao leite humano.

$\mathrm{Na}$ área cardiológica existem, em vez de marcapassos, sistemas de sensores que permitem o monitoramento de pessoas cardíacas. Se houver um fibrilamento ou interrupção do ritmo correto, é possível, imediatamente, tratá-las de forma emergencial. Esses aparelhos vêm sendo desen- 
volvidos rapidamente e logo permitirão um monitoramento contínuo.

$\mathrm{Na}$ área farmacêutica ocorre uma grande revolução, com produtos capazes de tratar doenças de origem genética, como Alzheimer. São produtos que lidam com mapas genéticos de cada indivíduo. Há novos preventivos de envelhecimento e drogas proporcionadoras de equilíbrio físico, que permitem um prolongamento da esperança de vida.

Os avanços tecnológicos da química chegaram ao ponto de hoje, termos os chamados produtos inteligentes, como o tecido cuja fibra aquece no frio e permite maior arejamento no calor. Esses produtos inteligentes aparecem também na área de transportes automotivos e aéreos. Existem tanques de gasolina para aviões que, pela própria constituição, fecham imediatamente caso sejam perfurados, desenvolvidos para o transporte aeromilitar e já adaptados para o transporte aerocivil.

A telefonia celular é um exemplo de tecnologia de ruptura. Ela não é a continuidade do telefone que conhecíamos no passado. Foi desenhada para novos usos e exige novas operações, não apenas uma aprendizagem, mas uma "desaprendizagem" em relação ao passado. Espera-se do indivíduo não só que ele incorpore o novo, mas esqueça parte do velho.

Quem viveu a era da substituição da máquina de escrever elétrica, aquela de esfera, para o computador, sabe quanto se resistiu à idéia de retirar a máquina de escrever da sala, querendo sempre mantê-la como uma espécie de refúgio visível do passado.

A informação permeia as ações da universidade. É o objetivo final da pesquisa e o que efetivamente se transmite nas atividades de ensino e de extensão. Descendente direta de estudos exploratórios desenvolvidos há décadas nos laboratórios acadêmicos, a tecnologia da informação volta à universidade como uma espécie de criatura que desafia o criador a decifrá-la incessantemente. O professor Imre Simon, presidente da Comissão de Informática da USP, alerta para o fato de que a partir da década de 50, quando foi iniciada a comercialização dos computadores, a cada 18 meses dobra a qualidade dos produtos disponíveis por um preço fixo. Ele revela: "Em mais 15 ou 20 anos poderemos adquirir a capacidade computacional de um computador caseiro atual por alguns reais. Alternativamente, poderemos comprar, pelos poucos milhares de reais que eles custam hoje, um verdadeiro supercomputador cujo preço atual seria de US\$ 2 milhões. Inimaginável!". O exemplo dado por Simon transmite uma idéia clara do vertiginoso ritmo de evolução desses meios e a conseqüente urgência de dominá-los a cada dia, principalmente na universidade - onde o conhecimento não pode parar sequer um segundo.

A universidade, como as pessoas, deve "desaprender" certos métodos, mas mantendo intacto o seu cabedal de conhecimentos. Não se trata de renunciar ao passado, apenas de preparar-se para o futuro com sabedoria, lançando mão das armas disponíveis.

A palavra impressa provocou uma revolução científica até 1800 e uma revolução tecnológica que começou a partir de então, durando até hoje. Por que? Porque a palavra impressa tornou acessível uma quantidade de informações que estava reservada para uma minoria. Quem leu O nome da rosa, de Umberto Eco, lembra-se de quão difícil era ter acesso aos manuscritos. Somente as igrejas tinham a possibilidade de guardá-los e alguns eram tão secretos a ponto de serem envenenados, para que os que manuseassem as suas páginas não sobrevivessem.

Houve, na história, duas transições fundamentais: uma da palavra falada para a palavra escrita, que permitiu as primeiras revoluções, e uma segunda, a partir de 1500 , da palavra escrita para a palavra impressa. Vivemos hoje um fenômeno semelhante com a palavra digital. O que se pode antecipar é que a mesma evolução de mentalidade que ocorreu ao longo desses últimos cinco séculos deve ocorrer, agora, numa intensidade ainda maior. O grande desafio que teremos pela frente será como preparar nossos quadros de referência para lidar com essa quantidade de informações e saber selecionar o que precisamos, dentro da extraordinária disponibilidade existente.

As novas tecnologias são facilmente captadas pelos jovens. Quando um novo equipamento é levado para casa, os filhos abrem a caixa e já começam a usar. Os pais descobrem a tecnologia com a leitura do manual. Os avós se distanciam da nova máquina, que os assusta e incomoda. Eles se sentem inferiorizados diante de uma criança de 8 ou 14 anos que tão familiarmente opera um computador, um vídeo, qualquer sistema eletrônico. A evolução tecnológica transforma rapidamente os sistemas de produção, distribuição e consumo, mas as habilidades humanas se alteram num ritmo bem menor.

Percebemos a existência de uma elite de inovadores na área de informática. Essas pessoas constituem uma família que lida com tecnologia mais avançada e acompanha a fronteira da tecnologia. Não devemos imitá-las, mas precisamos ouvi-las para melhorar nossas habilidades e incorporar com sabedoria a inovação, sem perder de vista os propósitos mais relevantes. Lembremo-nos sempre de 
que a tecnologia é um meio a serviço da humanidade e não o oposto.

\section{MUDANÇA DE ATITUDES}

Para se chegar a essa hipotética realidade em médio prazo, não basta investir pesadamente na compra de equipamentos. É necessário mudar a mentalidade dos usuários. É necessário iniciar, desde agora, entre os professores, um intenso esforço de "desaprendizagem", ou seja, o seu descolamento dos métodos que a tecnologia ultrapassou.

Por suas iniciativas a Comissão Central de Informática da USP ofereceu oportunidade de avaliar os frutos coletivos, assim como as perspectivas futuras dos usos da tecnologia de informação na pesquisa, no ensino e nas atividades de extensão. Uma conferência e um debate realizados em tempo real com interatividade entre o MIT e a USP revelaram que a tecnologia de informação é um componente a ser incorporado no processo pedagógico e de formação de lideranças. A tecnologia não substitui o docente, tampouco dispensa a interação em sala de aula. Acrescenta mais uma valiosa fonte de informação que torna acessível o conhecimento distante.

\section{LIMITES DA VIRTUALIDADE}

A relação da universidade com a tecnologia da informação suscita várias dúvidas. Seria possível o surgimento de uma universidade virtual? Como ficaria a relação professor/aluno?

Digamos, sem rodeios, tais hipóteses estão absolutamente descartadas. Pode e deve haver espaço para múltiplos meios de informação a distância, o que é outra coisa. O conceito de "Walk University" mostra curiosas possibilidades, mas julgamos a convivência humana insubstituível na comunidade acadêmica. Até para ensinar os alunos a usar a virtualidade e atualizá-los constantemente sobre os novos meios, a figura do professor é imprescindível. Há pessoas que julgam equivocadamente esgotada a era dos livros e impressos, porque eles estão disponíveis nos computadores. Mas se esquecem de que tal disponibilidade existe para consulta, e não para leitura. Haverá sempre escritores e leitores, como haverá sempre alunos e professores, convivendo e engendrando o futuro, em salas de aula, bibliotecas e laboratórios. Da palavra falada à escrita, e da palavra impressa à digitalizada, cada era enriqueceu a anterior, em vez de anular as suas conquistas.
Outra questão engenhosa, levantada pelos críticos da tecnologia da informação: como ficaria, por exemplo, a situação de um aluno de Letras, que conhece as principais obras da literatura universal e, no entanto, é um analfabeto em matéria de informática? Seria ele pior ou melhor aluno do que um bom "micreiro", sem formação literária?

Devemos responder enfaticamente, do ponto de vista do projeto universitário, interessa muito mais o aluno de Letras que conhece as melhores obras literárias do que um micreiro, por mais ágil que seja. $\mathrm{O}$ indivíduo que conhece a filosofia grega utilizou a palavra impressa para adquirir tal conhecimento. O micreiro domina o instrumento tecnológico, mas não alcançou esse nível de progresso intelectual. Certamente, nesse aspecto, é um atrasado. Mas o aluno de Letras, dominando a palavra digital, aumentará mais ainda a sua superioridade sobre o micreiro. Não há como desobrigar o homem moderno de acompanhar a evolução da informática e dominá-la para sua comodidade.

Um professor da Universidade de Nova York, Neil Postman, escreveu o livro Technopoly - the surrender of culture to technology, do qual faz parte o trecho seguinte: "Alguns professores aceitam, sem réplica, explicações que começam com as palavras: 'o computador está mostrando', ou, 'o computador determinou'. Tais palavras soam como o equivalente da frase: 'É a vontade de Deus"'. O computador, segundo Postman, é visto em algumas universidades como um todo-poderoso que pode nos transformar em milhões de Kafkas do século vindouro.

$\mathrm{O}$ autor exagera. A boa universidade tem suficiente senso crítico para desmistificar certos aspectos da tecnologia. Ela ajuda o ser humano a colocar a tecnologia a seu serviço, em vez de se submeter aos processos tecnológicos. Existe o risco, é claro, de tornar a tecnologia de informação um elemento hipnotizador e paralisante. Já se falou disso em algumas obras de ficção. Mas o indivíduo bem formado é obstáculo fundamental para deter qualquer movimento de desumanização do planeta. Pensemos positivamente. É surpreendente a utilidade dos novos meios na abertura do espaço da diversidade. O computador não diz a verdade única e definitiva. Ele nos mostra a imensa gama de respostas para cada questão e diminui a nossa arrogância. Mostra como é rico o pensamento humano, produzindo tantas respostas, e como é pobre a máquina, simplesmente operando como veículo para difundir essas respostas.

Mesmo compreendendo a importância da tecnologia da informação, devemos nos perguntar para onde ela vai daqui para a frente. Quais são os gargalos enfrentados pela universidade nesse processo de absorção de novas tecno- 
logias de informação? Algo que vem permeando toda a vida acadêmica é o confronto modernização versus modernidade. A universidade adquiriu símbolos de modernização, via equipamentos, mas não modificou suas formas de atuação no relacionamento com seus professores ou com os alunos. Se olharmos os modelos de relacionamento professor/professor, professor/aluno, é raro aquele, dentro da academia, que se modificou em decorrência do uso da tecnologia de informação.

A modernização tem símbolos aparentes de mudança. Orienta-se para o futuro. A modernidade é imediatamente absorvida, inserida no cotidiano, modificando as ações práticas entre os vários segmentos de uma comunidade. Basta ver quanto é difícil novos meios tecnológicos de informação permearem o comportamento de nosso quadro de funcionários. Um certo esforço de capacitação vem sendo feito, mas ainda está muito aquém do ideal.

Um segundo problema está na postura dos nossos jovens alunos, plenamente familiarizados com a modernização, mas descolados da modernidade, que, em última análise, é a percepção madura das transformações históricas. Para que a modernidade se materialize, não basta que tenhamos jovens nas atividades operacionais. Eles precisam muito mais do que aptidões. Impõe-se, por outro lado, uma verdadeira revolução cultural que permita aos mais velhos incorporar essas tecnologias ao seu dia-a-dia.

Muito preocupante, para dizer o mínimo, uma intervenção que testemunhamos no Mercosur Economic Summit, organizado em Buenos Aires pelo World Economic Forum. O seu autor não mediu palavras para definir as expectativas da indústria da informática em relação ao projeto pedagógico da América Latina. Citou, sem reservas, um pacto que teria sido firmado por autoridades na área educacional do continente, segundo o qual todas as escolas estarão conectadas até 2005 , por computadores. Não é preciso ser conservador para concluir que essa hipótese, aparentemente modernizadora, pode representar indesejável esterilização de padrões curriculares e desqualificação do papel dos professores.

Embora de grande valia na difusão de conhecimento, as novas tecnologias de informação jamais deverão inibir o papel transformador do ensino. Papel que consiste basicamente em fazer de cada aluno, depois de formado, um verdadeiro agente de mudanças.

Preparar agentes de mudanças para enfrentar os novos tempos exige mais do que tornar informações acessíveis para milhões de seres humanos. No século XV, quando surgiu a palavra impressa, o invento de Johann Gutemberg igualmente permitiu que a informação ampliasse fantasticamente o seu alcance. Mas tornou-se necessário transformar a informação em conhecimento e, depois, transformar o conhecimento em sabedoria. A sabedoria moveu Galileu Galilei e Isaac Newton e o conhecimento induziu a revolução tecnológica nos séculos XVIII e XIX.

Devemos reconhecer na telemática uma poderosa força difusora do saber, negada pelos retrógrados de hoje, tão renitentes quanto aqueles de épocas passadas. Também o invento de Gutemberg foi hostilizado e muitos autores não permitiram que o seu trabalho chegasse aos livros, por temer o que chamavam de incompreensão dos ignorantes. A história, esta sábia mestra, demonstrou exatamente o contrário: o livro é a melhor arma contra a ignorância. O livro mudou profundamente o papel do educador e a missão da escola. Tornou os professores ainda mais importantes para a estruturação dos projetos de vida dos jovens. Uma educação padronizada e submetida a interesses não pedagógicos causaria danos irreparáveis às novas gerações.

O desafio da educação é arquitetar novas mentalidades. Para tanto devemos buscar, dentro e fora da escola, a complementaridade em objetivos que muitos julgam antagônicos: indução do espírito empreendedor e trabalho em equipe; postura geoestratégica pró-ativa e respeito à diversidade; busca da excelência e preservação das diferenças de perspectiva; competição e cooperação; lógica de mercado e coesão social.

Eis, em resumo, os princípios para a construção da mentalidade de uma juventude nascida na década de 80 e que chegará ao ano 2080, pois é de aproximadamente 100 anos a esperança de vida projetada para as novas gerações. São princípios que refletem movimentos de integração e fragmentação, marcantes em nossa era, quando os meios digitalizados nos aproximam e o fosso socioeconômico nos distancia de forma crescente.

A educação é a força capaz de mediar os conflitos existentes e atenuar seus efeitos. Cabe usá-la com aguçado senso de valores impondo limites aos processos disponíveis, inclusive os da informática. Oferecer generalizadamente aos alunos um prato feito nos servidores eletrônicos, por exemplo, é procedimento que pode gerar a robotização da juventude e destruir valores essenciais. Sem falar no risco de acidentes como o ocorrido com a Associated Press, que publicou na Internet material guardado para uso em caso de falecimento do ator Bob Hope. Na hora em que milhões de pessoas tomavam conhecimento da notícia falsa e líderes políticos americanos formula- 
vam pêsames no Congresso, Hope, de 95 anos, dormia placidamente em sua casa. É fácil imaginar os efeitos de um erro dessa natureza em programas educacionais, difundidos em rede para todas as escolas do continente.

A educação é uma questão muito séria para ser decidida isoladamente por autoridades, fornecedores de equipamentos eletrônicos e provedores de serviços digitalizados. Embora os novos tempos exijam dos educadores um diálogo permanente com todos os segmentos da sociedade, em busca de currículos adequados ao mundo real, isso não deve implicar a serialização das consciências. Precisamos de uma pedagogia que harmonize visões de mundo com o ensino de competências específicas e novas habilidades.

Essa forma de pensar a educação não pode ser apenas teórica e imobilista. Foquemos alguns que resumem os conceitos gerais até aqui expostos nestas linhas: reconhecer que a juventude da década de 80 é muito diferente, talvez mesmo oposta àquela da década de 60 ; reconhecer que a educação dura a vida toda; reconhecer que a tecnologia tem um papel importante na educação das próximas gerações e na formação de mentalidades; reconhecer que uma visão de mundo é construída a partir da infância, na família, e tem o seu ponto de inflexão na escola, durante a juventude; integrar, no ensino, os projetos profissionais e os deveres de cidadania.

Ao discurso pragmático e sem nuanças que prega uma irrestrita apologia do ensino informatizado opõem-se, na rive gauche do pensamento, as teses de Viviane Forrester. Essa respeitável ensaísta do Le Monde agita o universo intelectual do mundo com o seu pequeno e inquietante livro chamado $O$ horror econômico, no qual proclama a impotência da sociedade para criar oportunidades de trabalho. São visões contraditórias em nosso tempo que somente a educação poderá filtrar, garantindo um sentido novo e construtivo para a aventura do homem.

A universidade não pode falar com desembaraço a respeito de modernidade se não demonstrar excelência no uso das novas tecnologias de informação. Não basta que professores e alunos usem computadores em suas tarefas cotidianas. É preciso que utilizem a web para a exposição de competências e permuta contínua de informações. Assim estarão praticando um exercício de inconformismo que divide uma era de conhecimento de outra. É preciso alimentar a idéia de que tudo pode ser melhor. Essa busca permanente de eficiência não é um procedimento empresarial, como alguns pensam. É antes de tudo um procedimento acadêmico, em sentido estrito. $\mathrm{Na}$ academia, nada está pronto, nada é definitivo, nada está completo.
Já dissemos em livro que não existe universidade perfeita. Grenoble, Harvard ou Tsukuba são apenas parte de um sonho inacabado. As variáveis para alcançarmos um modelo ideal multiplicam-se de tal forma que, em parte alguma, poderemos visualizá-lo. É próprio do pensar acadêmico enxergar o real como algo incompleto, que sempre exigirá um aperfeiçoamento.

Onde acharemos um corpo de professores absolutamente homogêneo pela excelência? Onde estarão os estudantes nivelados por cima, em sua totalidade? Onde haverá nas universidades grupos de administradores infalíveis, que possam exercer a gestão impecável? Em lugar nenhum.

O processo cumulativo de idéias trará resultados sempre insuficientes, mas cada vez mais úteis. Uma boa proposição pode sair de outra e deste modo, sucessivamente, tentamos abrir um caminho além do futuro imediato. Um futuro inalcançável - porque a existência humana tem limites - mas onde, afinal, restará alguma coisa, por mais ínfima que seja, do que pensamos e do que fizemos.

A missão acadêmica é algo que se reconceitua a cada época e jamais será definida com exatidão ao longo da história. A universidade passou a ser uma instituição transnacional. Impossível examiná-la somente à luz do seu entorno imediato. Se quisermos pensar adequadamente a universidade brasileira ou de qualquer outro país, teremos de contemplar o mundo em sua totalidade. São as transformações mundiais, em todas as áreas da atividade humana, que devem mover as estratégias acadêmicas. E, nesse cenário, as bem-vindas inovações da tecnologia de informação têm um papel irreversível.

\section{REFERÊNCIAS BIBLIOGRÁFICAS}

ECO, U. O nome da rosa. São Paulo, Nova Fronteira, 1987.

FORRESTER, V. O horror econômico. São Paulo, Unesp, 1997.

MARCOVITCH, J. A universidade (im)possivel. São Paulo, Futura/ Siciliano, 1997.

MORIN, E. La tête bien faite-Repenser la réforme, réformer la pensée. Paris, Éditions du Seuil, 1999.

POSTMAN, N. Tecnopólio: a rendição da cultura à tecnologia. (Trad. Reinaldo Guarany). São Paulo, Nobel, 1994.

USP. A USP e seus desafios: I Fórum de Politicas Universitárias: Módulo 1. São Paulo, Edusp, 2001a.

A USP e seus desafios: I Fórum de Politicas Universitárias: Módulos 2 e 3. São Paulo, Edusp, 2001 b.

JACQues Marcovitch: Professor da FEA-USP. Foi Reitor da Universidade de São Paulo. Atualmente é Secretário de Economia e Planejamento do Estado de São Paulo. 